\title{
Comparison of Respiratory Outcomes between Less Invasive Surfactant Administration and the Intubation- Surfactant-Extubation Technique in Premature Infants with Respiratory Distress Syndrome
}

Hye Seon Kim, MD, Hyun Ho Kim, MD, Misun Yang, MD, Yea Seul Han, MD, Se In Sung, MD, PhD, So Yoon Ahn, $\mathrm{MD}$, PhD, Yun Sil Chang, MD, PhD, and Won Soon Park, MD, PhD

Department of Pediatrics, Samsung Medical Center, Sungkyunkwan University School of Medicine, Seoul, Korea

\section{ABSTRACT}

Purpose: To compare respiratory outcomes between less invasive surfactant administration (LISA) and the intubation-surfactant-extubation (INSURE) technique in premature infants with respiratory distress syndrome (RDS).

Methods: We performed a retrospective medical chart review for 75 premature infants who were born at a gestational age (GA) of $\leq 34$ weeks (between January 2017 and December 2019) and developed RDS after birth. Data on the demographic and outcome variables, including respiratory outcomes, were collected and compared between the infants who received LISA and those who received INSURE as a rescue therapy for RDS.

Results: No signifcant differences in GA, birth weight, and other demographic characteristics were found between the LISA and INSURE groups (GA: 28.7 weeks vs. 28.8 weeks, $P=0.449$; birth weight: $1,236 \mathrm{~g}$ vs. $1,124 \mathrm{~g}, P=0.714$ ). At the delivery room, although the infants showed no significant difference in positive pressure ventilation rate after birth, the LISA group showed a higher rate of continuous positive airway pressure application than the INSURE group. The infants in the LISA group presented a higher risk of requiring multiple doses of surfactant for RDS than the infants in the INSURE group ( $57 \%$ vs. $17.5 \%, P=0.001$ ). However, the duration of invasive and/ or noninvasive respiratory support and incidence of bronchopulmonary dysplasia showed no signifciant difference between the two groups.

Conclusion: In the present study, no significant differences in the incidence of inhospital respiratory outcomes such as bronchopulmonary dysplasia were found between the LISA and INSURE groups. These results suggest that LISA can be an alternative therapeutic option for treating RDS to avoid intubation and mechanical ventilation in premature infants.

Key Words: Surface-active agents; Respiratory distress syndrome in premature infants
Received: 20 April 2020

Revised: 20 May 2020

Accepted: 21 July 2020

Correspondence to: Se In Sung, MD, PhD

Department of Pediatrics, Samsung Medical Center, Sungkyunkwan University School of Medicine, 81 Irwonro, Gangnam-gu, Seoul 06351, Korea

Tel: +82-2-3410-1775

Fax: +82-2-3410-0043

E-mail: sein.sung@samsung.com

Copyright(c)

By Korean Society of Neonatology.

All right reserved.

This is an Open-Access article distributed under the terms of the Creative Commons Attribution Non-Commercial License (http:// creativecommons.org/licenses/by-nc/4.0), which permits unrestricted non-commercial use, distribution, and reproduction in any medium, provided the original work is properly cited. 
서론

미숙아 호흡곤란증후군은 미숙아의 예후를 결정하는 흔하고 중 요한 합병증으로 알려져 있다. 미숙아 호흡곤란증후군 치료에서 폐 계면활성제의 투여는 호흡보조와 더불어 결정적인 치료법으로 그 시기와 방법에 대해 여러 연구가 진행되어 왔다 ${ }^{1,2)}$. 기존에는 기도 삽관, 폐계면활성제 투여 후 기계환기를 지속하다가 기계환기 이탈 을 시도하는 것이 가장 일반적이고 고식적인 치료법이었다. 하지만 이는 기도삽관 및 기계환기 지속이라는 침습적 조작이 불가피하고, 단기간의 기계환기 적용도 미숙아의 폐손상을 유발할 수 있음이 밝 혀지면서 비침습적 치료에 대한 관심이 증가하게 되었다 ${ }^{3-7)}$. 더 나아 가 호흡곤란증후군에서 폐계면활성제 투여 없이 지속성 양압환기 (continuous positive airway pressure, CPAP)가 기존 치료 대비 열 등하지 않음을 보여주는 여러 연구가 발표되었다 ${ }^{8-11}$. 이에 폐계면 활성제 투여의 장점을 취하는 한편 침습적 기계환기의 기간을 최소 화하기 위한 기도삽관-폐계면활성제 투여-발관을 연이어 시행하는 intubation-surfactant-extubation technique (INSURE) 법이 시도되 었다. 하지만 기도 삽관의 시행 자체가 진정제 투여가 필요하고 후 두 및 기관 등에 손상을 야기할 수 있으며 출생 직후에 혈역학적 불 안정성을 유발할 수 있는바, 기도 삽관을 배제하고 자발 호흡을 하 는 미숙아에서 비위관 등을 통해 폐계면활성제를 투여하는 새로운 방법이 개발되었으며 ${ }^{12-14)}$, 비슷한 여러 방법을 통칭하여 비침습적 폐계면활성제 투여법(less invasive surfactant administration, LISA; or minimally invasive surfactant therapy)이라고 불리게 되었다 ${ }^{15)}$.

본 병원에서는 이러한 치료 변화의 경향을 문헌고찰을 통해 파악 한 후 예방적 폐계면활성제 투여를 하던 방식을 중단하고 INSURE 법 및 LISA법을 점진적으로 적용하였다. LISA법은 INSURE법에 비 해 이론적으로 더욱 비침습적인 방법으로 여겨질 수 있으나 둘 간의 직접적 비교에 대한 국내외 연구는 많지 않았다. 이에 저자들은 본 병원의 치료 경험을 분석하여 INSURE법 대비 LISA법의 치료 안정 성과 효과를 비교 분석하고자 하였다.

\section{대상 및 방법}

\section{1. 연구 대상 및 디자인}

2017년 1월부터 2019년 12월까지 삼성서울병원에서 출생하여 신생아중환자실에 입원한 임신나이 25 주 이상 35 주 미만의 미숙아 75 명을 대상으로 하였고 이들의 의무기록을 후향적으로 분석하였 다. 미숙아 호흡곤란증후군에 대해 INSURE법을 사용한 군(2017년 1월-2018년 8월, n=40)과 LISA법을 사용한 군(2018년 9월-2019년 12 월, $n=35$ ) 간의 임상적 특성과 예후를 비교 분석하였다. 본 연구 는 연구자의 동의서 취득이 면제되었으며 삼성서울병원 임상시험
심사위원회의 승인(IRB No. 2020-04-129)을 받았다.

\section{2. 수집 데이터 항목 및 정의}

신생아중환자실에 입원한 임신나이 25 주 이상 35 주 미만의 미숙 아 75 명의 인구통계학적 특성과 출생시 분만장에서 시행한 소생술 과 호흡기계 보조 여부 및 사용 기간, 기관지폐이형성증의 이환율 및 기타 주요 신생아 합병증 이환율에 대하여 조사하였다. 인구 통 계학적 특성으로는 임신나이, 다태아 여부, 성별, 분만 방식, 출생 체 중, 부당경량아(small for gestational age; 10 백분위수 미만), 1 분 및 5 분 아프가 점수, 융모양막염, 산모의 당뇨병, 조기양막 파수, 산모 의 고혈압, 산전 스테로이드 및 마그네슘의 사용 등에 대하여 조사 하였다. 분만장에서 초기 소생술로 양압환기, 휴대용 비강 $\mathrm{CPAP}$ 기 계를 이용한 양압환기, 산소적용을 시행하였으며 출생 이후 첫 번째 폐표면활성제가 투약된 시간과 폐표면활성제의 투약횟수, 침습적 기계 호흡기 및 비강 $\mathrm{CPAP}$ (NCPAP)이나 고유량 비강 케뉼라(highflow nasal cannulae, HFNC)의 비침습적 기계 호흡기 필요 여부와 사용 기간, 산소 사용 기간 등을 조사하였다. 임상적 결과로 사망률 및 기관지폐이형성증 유병률, 흥관 삽관이 필요한 정도의 기흥 및 폐출혈 여부, 흡입성 일산화질소 치료가 필요한 폐동맥 고혈압, 3 단 계 이상의 뇌실 내 출혈, 레이져 및 수술적 치료가 필요한 미숙아 망 막증, modified Bell's staging criteria $^{16)}$ 에 의해 진단된 2기 이상의 괴 사성 장염, 폐혈증 등을 조사하였다.

일산화질소 치료가 필요한 폐동맥 고혈압은 심초음파 상 삼천판 역류의 압력차이가 $40 \mathrm{mmHg}$ 이상, 우심부전, $\mathrm{D}$ 자 모양의 좌심실, 동맥관 개존이나 난원공을 통한 우좌단락 또는 우좌단락이 우세인 양방향 단락 등이 확인될 때로 정의하였으며, 동맥관 전(preductal) 과 후(postductal)의 산소 포화도 차가 $10 \%$ 이상 지속적으로 관찰되 어 기계환기를 통한 산소를 사용한 경우도 포함하였다. 신생아 호 흡곤란증후군은 산소 요구도 증가, 빈호흡, 늑골간 당김 등의 뚜렷 한 호흡곤란 증후를 보이며 흥부방사선 사진상 폐용적의 감소 또 는 공기기관지조영상(air-bronchogram) 등의 의심 소견이 있어 폐 표면활성제를 투여받은 경우로 정의 하였다 ${ }^{17)}$. 임신나이 24 주 이하 또는 이후이어도 자발 호흡 노력이 없거나 현저히 부족한 경우에는 기도삽관 후 기계환기 치료를 시작하였으며, 임신나이 25 주 이상이 면서 자발호흡이 있는 경우에는 LISA법 또는 INSURE법을 시행하였 다. LISA법 또는 INSURE법으로 폐표면 활성제를 투여 받은 이후에 도 $\mathrm{FiO}_{2}$ 의 요구도가 0.6 이상으로 증가되고 모세혈관으로 시행한 혈 액 가스 검사에서 지속적인 호흡성 산증 $(\mathrm{pH}<7.2)$ 이 있거나 서맥을 동반한 무호흡이 빈번해지는 경우에 대해서는 기도삽관을 시행하 고 침습적 기계 호흡기를 적용하였으며, 이와같이 생후 72 시간 안에 기도삽관이 이루어진 경우 LISA 또는 INSURE 적용이 실패한 것으 로 정의하여 조사하였다. 


\section{INSURE/LISA 방법}

LISA법은 후두경을 이용하여 성대를 직접 본 후 5-6 Fr의 비위관 을 특별한 기구 없이 후두에서 1-2 cm 아래 위치까지 기관 내로 삽 입하고 후두경을 제거한 뒤 체중당 $120 \mathrm{mg}$ 의 폐표면활성제(Curosurf, Chiesi Farmaceutici, Parma, Italy)를 투여하였다. 폐표면활성 제는 약 1-2분에 걸쳐서 주입하며 주입 동안 NCPAP이나 HFNC를 적용한 상태를 유지하였다. INSURE법은 기관 내 튜브 삽관을 통해 서 LISA법에서 사용된 동량의 폐표면활성제를 환자의 하기도에 직 접 투여한 뒤 20/5-cm H $\mathrm{H}_{2} \mathrm{O}$ 의 압력으로 약 1 분간 양압환기를 실시하 고 즉시 발관한 뒤 $\mathrm{NCPAP}$ 를 적용하였다.

\section{4. 통계}

LISA군과 INSURE군 간의 비교에서 연속 변수들은 정규성 검정을 먼저 실시하여 만약 정규성을 따를 경우 Student $t$-test와 Wilcoxon rank sum test를 사용하여 분석하였으며 $P$ 값이 0.05 미만인 경우 를 통계학적으로 의미가 있다고 판단하였다. 범주형 변수들은 카이 제곱검정과 피셔검정을 사용하였다. 통계학적인 분석을 위해 SPSS software version 19.0 for Windows (IBM Co., Armonk, NY, USA) 를 사용하였다.

\section{결과}

LISA군과 INSURE군은 임신나이(28.7주 대 28.8주), 출생체중 $(1,236.6 \mathrm{~g}$ 대 $1,124.3 \mathrm{~g})$, 성별(60\% 대 65\%) 등을 비롯한 인구 통계
학적 특성에서 유의한 차이가 없었다(Table 1). 분만장에서의 초기 소생술 종류를 비교하였을 때 양압환기 및 산소적용을 한 경우의 차 이는 없었으나 LISA군에서 초기 소생술로 CPAP을 사용한 경우가 더 많았다 $(17 / 35,49 \%$ 대 10/40, 25\%, $P=0.033$ ) (Table 2). 호흡보 조 요법을 비교하였을 때 첫번째 폐표면활성제가 투여 되기까지 걸 리는 시간에는 두 군 간의 차이가 없었다. 또한 LISA법 또는 INSURE 법의 실패로 3 일 안에 기도 삽관을 하는 경우에도 두 군 간의 차이는 없었다. 하지만 LISA군에서 INSURE군보다 2회 이상의 폐표면활성 제 사용이 통계적으로 유의하게 높았다(20/35, 57\% 대 $7 / 40,40 \%$, $P=0.0004)$. 전체 입원 기간 중 기관삽관을 통한 침습적 호흡기계를 사용한 경우는 LISA군이 11명(31\%), INSURE군이 18명(55\%)이었 다. 침습적 기계환기와 비침습적 기계환기의 적용 기간과 비강 케뉼 라를 통한 산소 공급 기간에 있어 의미 있는 차이는 없었다.

또한 두 군 간의 입원 기간 중 사망률 $5.7 \%$ 대 $5.0 \%$ ) 및 중등도 이 상의 기관지폐이형성증 이환율(21.2\% 대 $18.4 \%)$ 을 비교하였을 때 통계적으로 유의미한 차이는 보이지 않았다(Table 3). 이 밖에 주요 합병증 이환율 또한 차이가 없었다. 단, 출생 후 LISA 또는 INSURE 실패로 기도삽관 후 기계환기를 적용하던 중 일산화질소 치료가 필 요할 정도의 폐동맥 고혈압을 보인 경우는 LISA군 $0 \%$ 대 INSURE군 $15 \%$ 로 의미 있는 차이를 보였다 $(P=0.027)$.

\section{고찰}

본 연구에서는 임신나이 25-35주의 미숙아 호흡곤란증후군 치료

Table 1. Patients' Demographic Characteristics

\begin{tabular}{|c|c|c|c|c|}
\hline Characteristic & LISA $(n=35)$ & INSURE $(n=40)$ & Total $(n=75)$ & $P$-value \\
\hline Gestational age (wk) & $28.7 \pm 2.1$ & $28.8 \pm 1.8$ & $28.8 \pm 1.9$ & 0.499 \\
\hline Singleton & $16(45.7)$ & $23(57.5)$ & $39(52.0)$ & 0.308 \\
\hline Male sex & $21(60.0)$ & $26(65.0)$ & $47(62.6)$ & 0.655 \\
\hline $\mathrm{C} / \mathrm{sec}$ & $31(88.5)$ & $34(85.0)$ & $65(86.6)$ & 0.742 \\
\hline Birth weight (g) & $1,236.6 \pm 482.0$ & $1,124.3 \pm 198.0$ & $1,176.7 \pm 361.3$ & 0.714 \\
\hline SGA & $5(14.2)$ & $8(20.0)$ & $13(17.3)$ & 0.514 \\
\hline 1 min Apgar score & $6.5 \pm 1.5$ & $6.7 \pm 1.6$ & $6.6 \pm 1.6$ & 0.303 \\
\hline 5 min Apgar score & $8.3 \pm 0.9$ & $8.58 \pm 0.9$ & $8.4 \pm 0.9$ & 0.109 \\
\hline Chorioamnionitis & $9(25.7)$ & $14(35.9)$ & $23(31.0)$ & 0.344 \\
\hline Maternal GDM & $0(0.0)$ & $3(7.5)$ & $3(4.0)$ & 0.243 \\
\hline PROM & $6(17.1)$ & $5(12.5)$ & $11(14.6)$ & 0.570 \\
\hline Maternal HTN & $9(25.7)$ & $8(20.0)$ & $17(22.6)$ & 0.555 \\
\hline Antenatal steroid & $34(97.1)$ & $40(100.0)$ & $74(98.6)$ & 0.466 \\
\hline Antenatal Mg & $8(22.8)$ & $11(27.5)$ & $19(25.3)$ & 0.644 \\
\hline
\end{tabular}

Values are expressed as mean \pm standard deviation or number (\%).

Abbreviations: LISA, less invasive surfactant administration; INSURE, INtubation SURfactant Extubation; C/sec, cesarean section; SGA, small for gestational age; GDM, gestational diabetes mellitus; PROM, premature rupture of membranes; HTN, hypertension; Mg, magnesium sulfate. 
Table 2. Resuscitation at the Delivery Room and Respiratory Management between the LISA and INSURE Groups

\begin{tabular}{|c|c|c|c|c|}
\hline Variable & LISA $(n=35)$ & INSURE $(n=40)$ & Total $(n=75)$ & $P$-value \\
\hline \multicolumn{5}{|l|}{ Resuscitation at delivery room } \\
\hline PPV at birth & $23(65.7)$ & $22(55.0)$ & $45(60.0)$ & 0.344 \\
\hline Primary stabilization with CPAP & $17(48.5)$ & $10(25.0)$ & $27(36.0)$ & 0.033 \\
\hline $\mathrm{O}_{2}$ apply in the delivery room & $32(91.4)$ & $34(85.0)$ & $66(88.0)$ & 0.489 \\
\hline \multicolumn{5}{|l|}{ Respiratory support } \\
\hline Age (min of life) at 1st surfactant & $156.4 \pm 481.9$ & $168.6 \pm 317.2$ & $162.9 \pm 399.7$ & 0.255 \\
\hline Need for $>1$ dose of surfactant & $20(57.1)$ & $7(17.5)$ & $27(36.0)$ & 0.001 \\
\hline IMV during first $3 \mathrm{~d}$ & $7(20.0)$ & $11(27.5)$ & $18(24.0)$ & 0.702 \\
\hline IMV anytime & $11(31.4)$ & $18(55.0)$ & $29(38.6)$ & 0.228 \\
\hline IMV duration (d) & $4.9 \pm 10.2$ & $5.2 \pm 11.3$ & $5.1 \pm 10.7$ & 0.240 \\
\hline NIMV (CPAP or HF) duration (d) & $17.4 \pm 17.6$ & $21.5 \pm 23.2$ & $19.6 \pm 20.7$ & 0.647 \\
\hline $\mathrm{Nasal} \mathrm{O}_{2}$ duration (d) & $8.7 \pm 14.9$ & $9.4 \pm 16.7$ & $9.1 \pm 15.8$ & 0.309 \\
\hline
\end{tabular}

Values are expressed as number (\%) or mean \pm standard deviation.

Abbreviations: LISA, less invasive surfactant administration; INSURE, INtubation SURfactant Extubation; PPV, positive pressure ventilation; CPAP, continuous positive airway pressure; IMV, invasive mechanical ventilation; NIMV, noninvasive mechanical ventilation; HF, high flow.

Table 3. Pulmonary and Neonatal Outcomes in the LISA and INSURE Groups

\begin{tabular}{|c|c|c|c|c|}
\hline Variable & LISA $(n=35)$ & INSURE $(n=40)$ & Total $(n=75)$ & $P$-value \\
\hline \multicolumn{5}{|l|}{ Respiratory outcomes } \\
\hline Moderate to severe BPD & $7(21.2)$ & $7(18.4)$ & $14(19.7)$ & 0.768 \\
\hline Pulmonary hemorrhage & 0 & $3(7.5)$ & $3(4.0)$ & 0.243 \\
\hline Pneumothorax & $1(2.8)$ & $2(5.0)$ & $3(4.0)$ & 1.000 \\
\hline Pulmonary hypertension & 0 & $6(15.0)$ & $6(8.0)$ & 0.027 \\
\hline \multicolumn{5}{|l|}{ Neonatal mortality and morbidities } \\
\hline Mortality during hospitalization & $2(5.7)$ & $2(5.0)$ & $4(5.3)$ & 1.000 \\
\hline Hospital stay (d) & $69.3 \pm 35.1$ & $75.8 \pm 48.9$ & $72.8 \pm 42.8$ & 0.932 \\
\hline $\mathrm{IVH}(\geq$ Grade 3$)$ & $1(2.8)$ & $4(10.0)$ & $5(6.6)$ & 0.363 \\
\hline PVL & 0 & $1(2.5)$ & $1(1.3)$ & 1.000 \\
\hline ROP (laser Op) & $2(11.7)$ & $1(6.2)$ & $3(9.0)$ & 1.000 \\
\hline NEC ( $\geq$ stage 2$)$ & $2(5.7)$ & $2(5.0)$ & $4(5.3)$ & 1.000 \\
\hline SIP & 0 & $1(2.5)$ & $1(1.3)$ & 1.000 \\
\hline Sepsis & $2(5.7)$ & $3(7.5)$ & $5(6.6)$ & 1.000 \\
\hline
\end{tabular}

Values are expressed as number (\%) or mean \pm standard deviation.

Abbreviations: LISA, less invasive surfactant administration; INSURE, INtubation SURfactant Extubation; BPD, bronchopulmonary dysplasia; IVH, intraventricular hemorrhage; PVL, periventricular leukomalacia; ROP, retinopathy of prematurity; Op, operation; NEC, necrotizing enterocolitis; SIP, spontaneous intestinal perforation.

로 INSURE법과 LISA법을 비교하였으며, 폐계면활성제 투여 후 침 습적/비침습적 호흡보조의 빈도나 기간 및 이후 기관지폐이형성증 발생에 두 군 간의 차이가 없음을 확인하였다. 저자들이 아는 한으 로는 폐계면활성제의 두 가지 투여 방식에 대한 국내 비교는 아직 없었다.

1984년에 Jobe와 Bancalari 등'이 동물실험을 통해 출생 직후 액 체로 찬 폐에 계면활성제를 투여하였을 때 더욱 균일한 폐계면활성 제의 분포를 보임을 발표한 이후 많은 인간 대상의 임상시험을 통해
폐계면활성제 조기투여의 효과가 입증되었으며, 2001년 Cochrane systematic review에서의 메타분석에서도 폐계면활성제의 예방적 투여가 선택적 투여에 비해 사망률을 감소시키는 등 예후를 향상시 킨다고 발표하였다 ${ }^{18)}$. 하지만 다른 한편으로는 단기간의 기계환기 로도 미성숙한 폐조직의 손상을 유발할 수 있음이 밝혀지고, 더 나 아가 Schmolzer 등8)의 메타분석에 따르면 출생 직후 기도삽관 및 침 습적 기계환기를 피하고 NCPAP을 적용하는 것이 추후 기관지폐이 형성증의 발생과 그로 인한 사망을 줄인다는 보고가 발표되었다. 이 
러한 딜레마가 지속되던 중 폐계면활성제 조기투여와 침습적 기계 환기 회피의 두 목표를 동시에 달성하기 위해 여러 가지 방식의 변 형된 치료법이 개발되었다.

폐계면활성제 투여 없이 비침습적 환기법을 일차 치료로 적용한 이후 일정 시간이 지나고 나서 발생하는 호흡곤란증후군의 경우에 는 결국 기관삽관을 시행하게 된다. 이러한 문제점을 극복하기 위 해 Verder 등 ${ }^{19,20)}$ 은 INSURE법을 개발하여 두 차례의 임상시험 결과 를 발표하였고 이후 많은 병원이 이 방식을 임상에 적용하였다. 그 러나 이 방법도 전처치로 사용하는 진정제에 따른 부작용, 서맥, 저 혈압 및 기도삽관의 기술적 어려움 등이 있었기 때문에 얇은 카테터 를 이용한 기관 카테터주입 방식이 Dargaville 등 ${ }^{21)}$ 에 의해 고안되었 다. 이에 대한 연구들은 기존 기관삽관을 지속하던 것에 비해 효과 적이었다.

하지만 INSURE법과 LISA법의 안정성과 효과에 대해 직접 비교 를 한 연구는 많지 않다. 임신 주수 32 주에서 36주의 신생아 호흡곤 란증의 미숙아 97명을 대상으로 한 Yang 등 ${ }^{22}$ 의 연구에서 본 연구 와 마찬가지로 호흡기 보조 정도의 차이 및 기관지폐이형성증 이환 율 등에 차이는 없었으나 시술 시행 동안 LISA군에서 혈압과 산소포 화도가 안정적으로 유지되는 것을 확인 할 수 있었다. 또한 Brew 등 ${ }^{3)}$ 과 More 등 ${ }^{13)}$ 의 연구에서도 마찬가지로 기관지폐이형성증 이환율 에는 두 방법 간의 차이가 없었으나 LISA법에서 기계호흡기 치료의 기간이 연장되었다. 반면 최근의 Kribs 등 ${ }^{23)}$ 에 의한 임상시험 결과 와 임신나이 31주 미만의 미숙아를 대상으로 한 다중 입력 데이터 분석 연구에서는 기관지폐이형성증 이환율 및 사망률이 유의하게 감소하였다.

본 연구에서는 단기간의 호흡기적 임상결과인 폐표면활성제 치 료의 실패 여부, 호흡기 보조의 정도와 기간에 차이가 없었고 기관 지폐이형성증 이환율 및 사망률에서도 차이가 없었다. 그러나 연구 기간 동안 후반부에 해당하는 LISA를 사용했던 기간은 본원에서 분 만장 $\mathrm{CPAP}$ 사용을 장려하였던 기간과 교차되며 이러한 $\mathrm{CPAP}$ 사용 이 호흡을 조기에 안정시켰을 가능성이 있다. 또한 LISA군에서 다 회투여가 많았는데 이는 기도삽관을 해야 하는 INSURE법에 비해 LISA법에 대한 의료진의 거부감이 적었기 때문일 가능성도 배제할 수 없다. 본 연구에서 특징적으로 LISA군에서는 폐동맥고혈압이 없 었던데 반해 INSURE군에서는 $15 \%$ 에서 일산화질소 치료를 필요하 는 폐동맥고혈압이 발생하였다. 이는 INSURE군에서 분만장 CPAP 에 의한 호흡 조기 안정화가 덜 적극적으로 시행 된 상태에서 침습적 시술인 기관삽관을 시행하였을 때 호흡기계의 불안정성에 이은 혈 역학적 불안정성이 촉발되어 폐동맥고혈압을 초래하였을 가능성이 있다. 본 연구의 한계로는 단일기관에서의 소규모 후향적 연구라는 점, 분만장에서의 $\mathrm{CPAP}$ 사용 빈도 차이 등이 교란변수로 작용할 수 있는 점 등을 들 수 있다. 또한 LISA 또는 INSURE 시술 자체의 부작 용 예를 들면 미주신경반사에 의한 서맥, 저혈압 등의 데이터를 수
집하지는 못하였다는 점 등을 들 수 있다 ${ }^{24-26)}$.

결론적으로 저자들은 본원에서 LISA법과 INSURE법을 시행한 미 숙아에서 현재까지는 임상적 결과의 차이가 없음을 알 수 있었다. 그러나 침습적 기도삽관 등을 피할 수 있는 LISA법의 이론적 장점이 뚜렷하므로 본 연구의 한계점을 고려한 향후 대규모 전향적 연구가 필요할 것이다.

\section{ARTICLE INFORMATION}

\section{Ethical statement}

This study was approved by the Institutional Review Board for Clinical Research at Samsung Medical Center (IRB No. 202004- 129). The IRB waived the need for informed consent for this retrospective chart review.

\section{Conflicts of interest}

No potential conflict of interest relevant to this article was reported.

\section{Author contributions}

Conception or design: H.S.K., H.H.K., M.Y., Y.S.H., S.Y.A., Y.S.C., W.S.P.

Acquisition, analysis, or interpretation of data: H.S.K.

Drafting the work or revising: H.S.K., S.I.S.

Final approval of the manuscript: S.I.S.

\section{ORCID}

Hye Seon Kim https://orcid.org/0000-0002-3909-2737

Se In Sung https://orcid.org/0000-0002-8717-6142

\section{Acknowledgments}

None

\section{REFERRENCES}

1. Jobe AH, Bancalari E. Bronchopulmonary dysplasia. Am J Respir Crit Care Med 2001;163:1723-9.

2. Bancalari E, del Moral T. Bronchopulmonary dysplasia and surfactant. Biol Neonate 2001;80 Suppl 1:7-13.

3. Brew N, Hooper SB, Allison BJ, Wallace MJ, Harding R. Injury and repair in the very immature lung following brief mechanical ventilation. Am J Physiol Lung Cell Mol Physiol 2011;301:L917- 
26.

4. Stevens TP, Harrington EW, Blennow M, Soll RF. Early surfactant administration with brief ventilation vs. selective surfactant and continued mechanical ventilation for preterm infants with or at risk for respiratory distress syndrome. Cochrane Database Syst Rev 2007;4:CD003063.

5. Aguar M, Vento M, Dargaville PA. Minimally invasive surfactant therapy: an update. NeoReviews 2014;15:e275-85.

6. Isayama T, Iwami H, McDonald S, Beyene J. Association of noninvasive ventilation strategies with mortality and bronch opulmonary dysplasia among preterm infants: a systematic review and meta-analysis. JAMA 2016;316:611-24.

7. Fischer HS, Buhrer C. Avoiding endotracheal ventilation to pre vent bronchopulmonary dysplasia: a meta-analysis. Pediatrics 2013;132:e1351-60.

8. Schmolzer GM, Kumar M, Pichler G, Aziz K, O'Reilly M, Cheung PY. Non-invasive versus invasive respiratory support in preterm infants at birth: systematic review and meta-analysis. BMJ 2013; 347:f5980.

9. Aly H, Milner JD, Patel K, El-Mohandes AA. Does the experience with the use of nasal continuous positive airway pressure im prove over time in extremely low birth weight infants? Pediatrics 2004;114:697-702.

10. Subramaniam P, Ho JJ, Davis PG. Prophylactic nasal continuous positive airway pressure for preventing morbidity and mortality in very preterm infants. Cochrane Database Syst Rev 2016;6: CD001243.

11. Finer N. To intubate or not, that is the question: continuous positive airway pressure versus surfactant and extremely low birthweight infants. Arch Dis Child Fetal Neonatal Ed 2006;91: F392-4.

12. Berneau P, Nguyen Phuc Thu T, Pladys P, Beuchee A. Impact of surfactant administration through a thin catheter in the delivery room: a quality control chart analysis coupled with a propensity score matched cohort study in preterm infants. PLoS One 2018; 13:e0208252.

13. More K, Sakhuja P, Shah PS. Minimally invasive surfactant administration in preterm infants: a meta-narrative review. JAMA Pediatr 2014;168:901-8.

14. Herting E. Less invasive surfactant administration (LISA): ways to deliver surfactant in spontaneously breathing infants. Early Hum Dev 2013;89:875-80.

15. Halim A, Shirazi H, Riaz S, Gul SS, Ali W. Less invasive surfactant administration in preterm infants with respiratory distress syndrome. J Coll Physicians Surg Pak2019;29:226-330.

16. Gregory KE, Deforge CE, Natale KM, Phillips M, Van Marter LJ. Necrotizing enterocolitis in the premature infant: neonatal nursing assessment, disease pathogenesis, and clinical presentation. Adv Neonatal Care 2011;11:155-64.

17. Roggini M, Pepino D, D'Avanzo M, Andreoli GM, Ceccanti S, Capocaccia P. Respiratory distress in newborn: evaluation of chest X-rays. Minerva Pediatr 2010;62:217-9.

18. Soll RF, Morley CJ. Prophylactic versus selective use of surfactant in preventing morbidity and mortality in preterm infants. Cochrane Database Syst Rev 2001;2:CD000510.

19. Verder H, Albertsen P, Ebbesen F, Greisen G, Robertson B, Bertelsen A, et al. Nasal continuous positive airway pressure and early surfactant therapy for respiratory distress syndrome in newborns of less than 30 weeks' gestation. Pediatrics 1999; 103:E24.

20. Verder H, Robertson B, Greisen G, Ebbesen F, Albertsen P, Lundstrom K, et al. Surfactant therapy and nasal continuous positive airway pressure for newborns with respiratory distress syndrome. Danish-Swedish Multicenter Study Group. N Engl J Med 1994;331:1051-5.

21. Dargaville PA, Aiyappan A, Cornelius A, Williams C, De Paoli AG. Preliminary evaluation of a new technique of minimally invasive surfactant therapy. Arch Dis Child Fetal Neonatal Ed 2011;96:F243-8.

22. Yang G, Hei M, Xue Z, Zhao Y, Zhang X, Wang C. Effects of less invasive surfactant administration (LISA) via a gastric tube on the treatment of respiratory distress syndrome in premature infants aged 32 to 36 weeks. Medicine (Baltimore) 2020;99: e19216.

23. Kribs A, Hartel C, Kattner E, Vochem M, Kuster H, Moller J, et al. Surfactant without intubation in preterm infants with respiratory distress: first multi-center data. Klin Padiatr 2010; 222:13-7.

24. Herting E, Hartel C, Gopel W. Less invasive surfactant administration (LISA): chances and limitations. Arch Dis Child Fetal Neonatal Ed 2019;104:F655-9.

25. Niemarkt HJ, Kuypers E, Jellema R, Ophelders D, Hutten M, Nikiforou M, et al. Effects of less-invasive surfactant administration on oxygenation, pulmonary surfactant distribution, and lung compliance in spontaneously breathing preterm lambs. Pediatr Res 2014;76:166-70.

26. Hartel C, Paul P, Hanke K, Humberg A, Kribs A, Mehler K, et al. Less invasive surfactant administration and complications of preterm birth. Sci Rep 2018;8:8333. 